\title{
Immunohistochemical Analysis of RCAS1 in Human Pituitary Adenomas
}

Katsuya Umeoka, Naoko Sanno, Kenichi Oyama, Shigeyuki Tahara, Reiko Kurotani, Shoichiro Ikuyama, Manabu Nakashima, Takeshi Wtanabe, R. Yoshiyuki Osamura, Akira Teramoto

Department of Neurosurgery (KU, NS, KO, ST, AT), Nippon Medical School, Tokyo, Japan; Department of Pathology (RK, RYO), Tokai University School of Medicine, Boseidai, Isehara-City, Kanagawa, Japan; Department of Clinical Immunology, Medical Institute of Bioregulation (SI), Kyushu University, Beppu, Japan; and Department of Molecular Immunology (MN, TW), Medical Institute of Bioregulation, Kyushu University, Fukuoka, Japan

It has been reported that RCAS1 (receptor-binding cancer antigen expressed on SiSO cells) acts as a ligand for a receptor present on normal peripheral lymphocytes and induces apoptotic cell death. It is expressed in uterine and ovarian carcinomas, especially in invasive cancers. This immunohistochemical study is aimed to elucidate the expression of RCAS1 in human pituitary adenomas in order to clarify its role in their proliferative regulation and invasiveness. Five normal pituitary glands, 50 human pituitary adenomas, and one malignant glioma were subjected to immunohistochemical studies. In normal pituitary glands, immunostaining of RCAS1 and MIB-1 was not found. In malignant glioma, large numbers of cell nuclei were positive for MIB-1 (MIB-1 index: 28\%), and RCAS1 was detected both in the cytoplasm and on the membrane of the tumor cells. Expression of RCAS1 was noted in $48 \%$ of pituitary adenomas immunohistochemically $\mathbf{6 0 . 0 \%}$ of growth hormone-secreting adenomas, $60.0 \%$ of prolactin-secreting adenomas, $42.9 \%$ of adrenocorticotrophin-secreting adenomas, $40.0 \%$ of thyroid-stimulating hormone-secreting adenomas, $33.3 \%$ of nonfunctioning adenomas, and $44.4 \%$ of gonadotropin-subunit-positive adenomas). It showed no correlation with tumor type, size, and invasiveness. The statistically significant relationship between RCAS1 and MIB-1 positivity was identified in our study. These results suggest that expression of RCAS1 as well as MIB-1 positivity predict the growth potential of individual pituitary adenomas.
KEY WORDS: Immunohistochemical examination, MIB-1, Pituitary adenoma, Proliferation, RCAS1.

Mod Pathol 2001;14(12):1232-1236

Most pituitary adenomas grow slowly and are considered benign (1). Some adenomas, however, grow rapidly despite their benign histologic features and invade the cavernous sinus $(2,3)$. The histopathologic findings often do not predict the biologic behavior of these atypical tumors $(4,5)$.

The monoclonal antibody MIB-1 was produced by using a recombinant peptide corresponding to part of the Ki-67 antigen (6, 7). The MIB-1 labeling index was used to assess the tumor proliferation and invasiveness (8). RCAS1 (receptor-binding cancer antigen expressed on SiSO cells), a membrane molecule expressed on human cancer cells, was isolated from 22-1-1. It acts as a ligand for a receptor present on normal peripheral lymphocytes such as T-, B-, and NK-cells and induces apoptotic cell death (9). Based on immunohistochemical analysis, RCAS1 is expressed in uterine and ovarian carcinomas and is especially strongly expressed in invasive cancers $(10,11)$.

In this study, we investigated the expression of RCAS1 in normal human pituitary glands and various types of human pituitary adenomas immunohistochemically to determine whether there was a correlation with the biologic behavior of individual tumors. In addition, we examined the relationship between the expression of RCAS1 and MIB-1 indexes.

\section{MATERIALS AND METHODS}

\section{Patients}

We studied five normal human pituitary glands obtained from autopsy within 4 hours of the patients' deaths without endocrinologic abnormali- 
ties, 50 cases of pituitary adenomas (24 male and 26 female, age ranged from 23 to 80 years) obtained by transsphenoidal surgery, and one malignant glioma resected by surgery. The clinical and endocrinologic features of pituitary adenomas were as follows: 10 patients with growth hormone-secreting adenomas, 10 with prolactin-secreting adenomas, seven with adrenocorticotrophin-secreting adenomas, five with thyroid-stimulating hormonesecreting adenomas, 18 with clinically nonfunctioning adenomas (nine with gonadotroph-secreting adenomas and nine with nonsecreting adenomas). The adenomas were classified based on their clinical manifestation, biologic functions, and ultra structures $(12,13)$. Tumor size and invasiveness were evaluated from gadolinium-enhanced magnetic resonance image. The "microadenoma" is defined as the tumor less than $10 \mathrm{~mm}$; in contrast, the "macroadenoma" is larger than $10 \mathrm{~mm}$. The "enclosed" tumor is better defined as "well demarcated" in contrast to "invasive."

\section{Tissue Preparation and Antibodies}

The tissues were routinely fixed in $10 \%$ formalin for 8 to 24 hours and embedded in paraffin. Five micron serial sections were deparaffinized in xylene and dehydrated in graded ethanols. Endogenous peroxidase activity was blocked with $0.3 \%$ hydrogen peroxide in methanol for 30 minutes. Immunostaining was performed using the avidin-biotinperoxidase complex technique. A monoclonal antibody against RCAS1 (22-1-1 hybridoma culture supernatant fluid) was applied at dilution 1:4 (911 ), and the slides were incubated for 3 hours. The antibody was kindly supplied by Dr. Shoichiro Ikuyama. As positive control, the sections of gliomas were used. Immunostaining for MIB-1 was detected as follows: the sections were treated by microwave for 10 minutes at $100^{\circ} \mathrm{C}$ in $0.01 \mathrm{~mol} / \mathrm{L}$ citrate buffer $\mathrm{pH} 6.0$ for antigen retrieval, and monoclonal antibody against MIB-1 (Immunotech, Marseille, France) was applied at dilution 1:100 for 60 minutes. The reaction was visualized by incubation with 3,3'-diaminobenzidine tetrahydrochloride for 3 minutes, which resulted in a brown color. Sections were then counter-stained in methyl green and mounted in Permount.

The MIB-1 immunoreactive nuclear index (MIB-1 index) was calculated as the percentage of immunopositive nuclei; vascular components and hematogenous cells were excluded. More than 1000 cells from each specimen were counted in several viable areas of tissue in which positive nuclei were evenly distributed. For statistical analysis of relationship with MIB-1 index and RCAS1 positivity, KruskalWallis test was applied. A statistically significant difference was defined as a $P$-value less than .05 .

\section{RESULTS}

\section{Immunostaining of RCAS1 and MIB-1}

In normal pituitary glands, immunostaining of RCAS1 and MIB-1 was not found. In malignant glioma, a large number of cells were positive for MIB-1 (MIB-1 index: 28\%), and RCAS1 was detected both in the cytoplasm and on the membrane of the most of tumor cells (Fig. 1). Expression of RCAS1 was noted in $48 \%$ of pituitary adenomas stained by immunohistochemistry (Fig. 2) $(60.0 \%$ of growth hormone-secreting adenomas, $60.0 \%$ of prolactinsecreting adenomas, $42.9 \%$ of adrenocorticotrophinsecreting adenomas, $40.0 \%$ of thyroid-stimulating

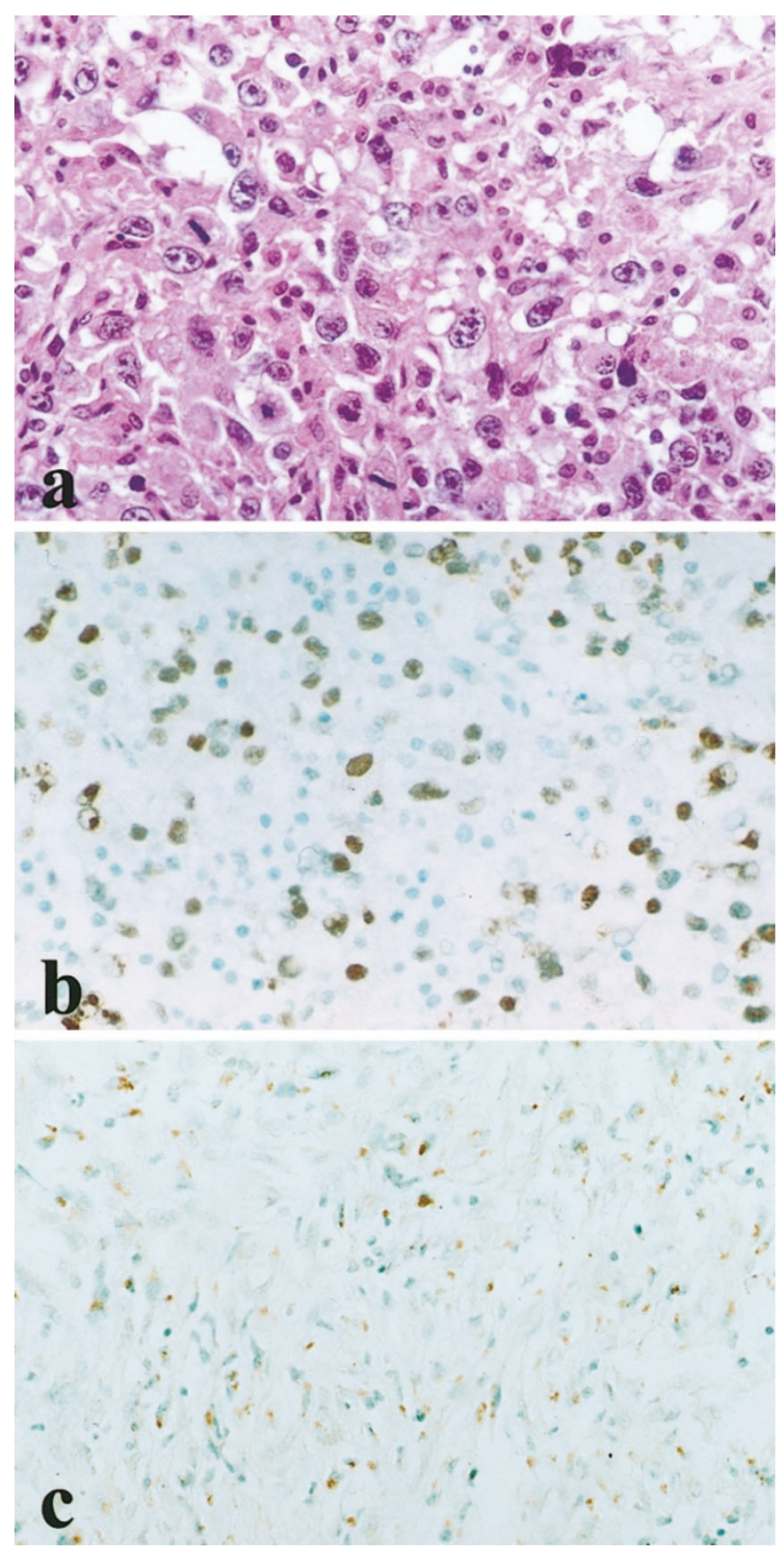

FIGURE 1. Hematoxylin and eosin staining (A) and immunostaining for MIB-1 (B) and RCAS1 (C) in glioma. B, A large number of tumor cells positive (\%) for MIB-1. C, Staining of same tumor shows relevantly higher positivity expression for RCAS1. 


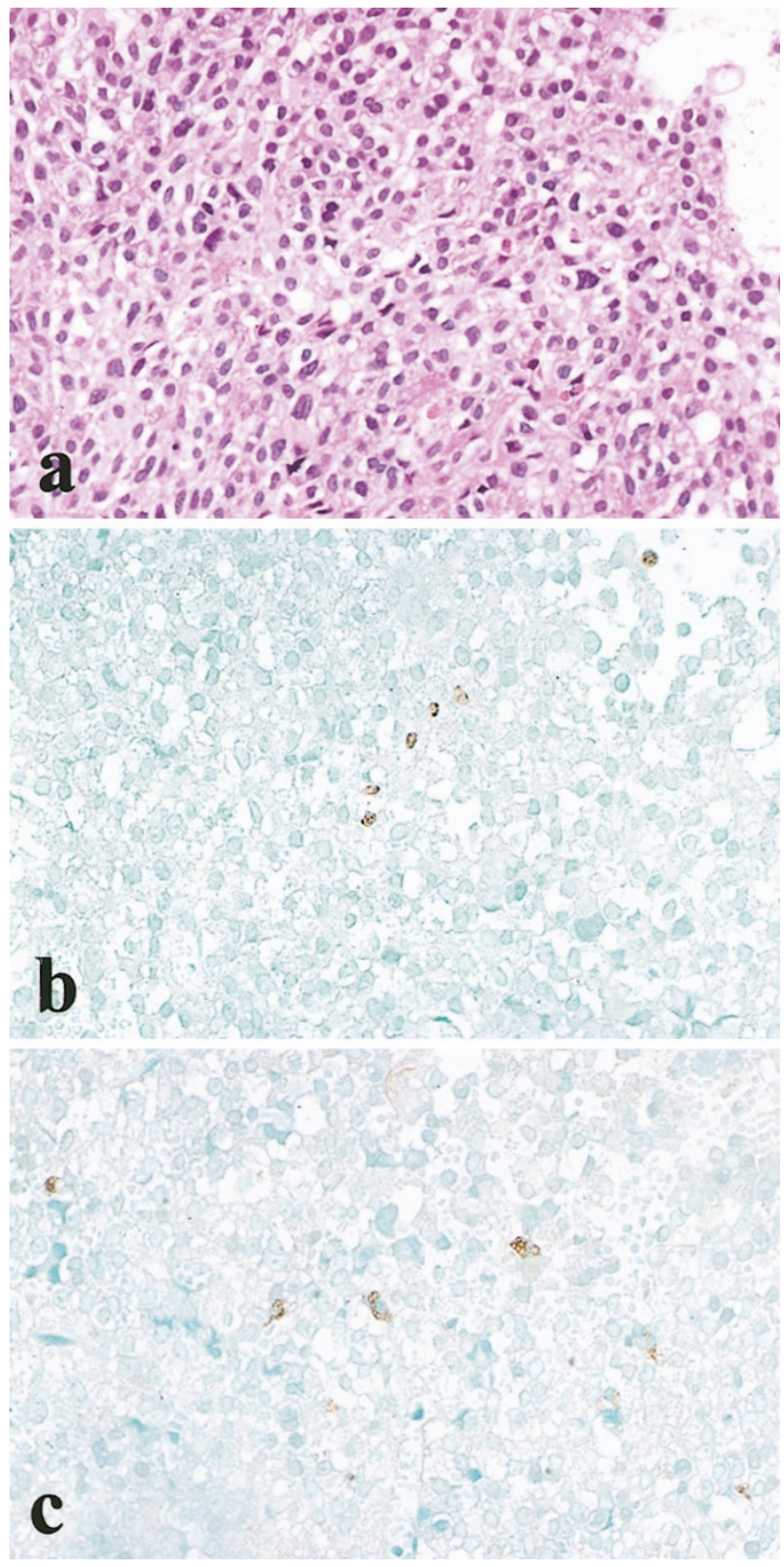

FIGURE 2. Hematoxylin and eosin staining (A) and immunostaining for (A) MIB-1 and (B) RCAS1 in prolactin-secreting pituitary adenoma.

hormone-secreting adenomas, $33.3 \%$ of nonfunctioning adenomas, and $44.4 \%$ of gonadotropinsubunit-positive adenomas). Kruskal-Wallis test proved no statistical correlation between immunohistochemical expression of RCAS1 and types of pituitary adenomas (Table 1). Expression of RCAS1 showed $48.0 \%$ of microadenomas and macroadenomas. RCAS1 showed $31.6 \%$ of noninvasive adenomas and $58.1 \%$ of invasive adenomas. Expressions of RCAS1 were not correlated with tumor size and invasiveness (Tables 2 and 3). Relationship between RCAS1 expression and MIB-1 index was statistically proven in this study (Fig. 3). The mean MIB-1 index values \pm SD were found: RCAS1-
TABLE 1. Immunohistochemical Expression of RCAS1 in Pituitary Adenomas

\begin{tabular}{lc}
\hline \multicolumn{1}{c}{ Type of Pituitary Adenomas } & $\begin{array}{c}\text { RCAS1-Positive/ } \\
\text { Number of } \\
\text { Adenomas } \\
\text { Studied }\end{array}$ \\
\hline Growth hormone-secreting adenomas & $6 / 10$ \\
Prolactin-secreting adenomas & $6 / 10$ \\
Adrenocorticotrophin-secreting adenomas & $3 / 7$ \\
Thyroid-stimulating hormone-secreting adenomas & $2 / 5$ \\
Nonfunctioning adenomas & $3 / 9$ \\
Gonadotropin-subunit positive adenomas & $4 / 9$ \\
\hline
\end{tabular}

TABLE 2. Relationship between Expression of RCAS1 and Size of Pituitary Adenoma

\begin{tabular}{lccc}
\hline Size of Adenoma & RCAS1-Positive & RCAS1-Negative & $\begin{array}{c}\text { Mann-Whitney } \\
\text { U-Test }\end{array}$ \\
\hline Microadenomas & 12 & 13 & \\
Macroadenomas & 12 & 13 & $P>.999$ \\
\hline
\end{tabular}

TABLE 3. Expression of RCAS1 and Invasiveness of Adenoma

\begin{tabular}{lccc}
\hline & RCAS1-Positive & RCAS1-Negative & $\begin{array}{c}\text { Mann-Whitney } \\
\text { U-Test }\end{array}$ \\
\hline Enclosed & 6 & 13 & \\
Invasive & 18 & 13 & $P=.717$ \\
\hline
\end{tabular}

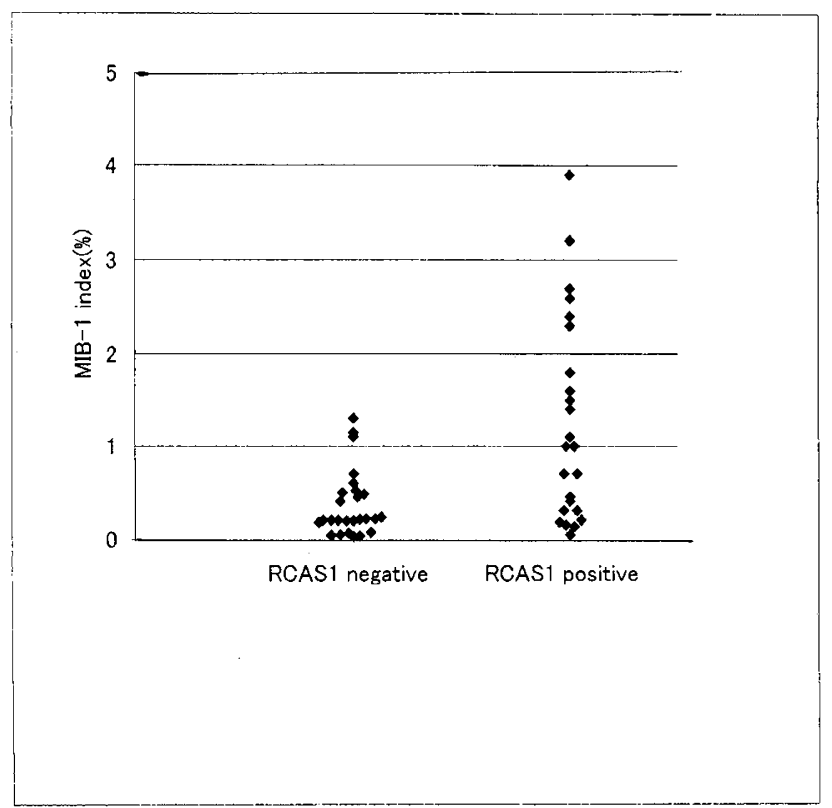

FIGURE 3. Frequency distribution of individual Ki-67 labeling index.

positive adenomas $(n=24), 1.222 \pm 1.067$; RCAS1negative adenomas $(n=26), 0.326 \pm 0.311 \%(P<$ $.001)$. [Table 4]

\section{DISCUSSION}

Pituitary adenomas are benign tumors, but they frequently invade surrounding structures such as 
TABLE 4. Relationship between RCAS1 and Ki-67 Labeling Index

\begin{tabular}{lccc}
\hline & $n$ & Mean \pm Standard Deviation & T-Test \\
\hline RCAS1-positive & 24 & $0.326 \pm 0.311$ & \\
RCAS1-negative & 26 & $1.222 \pm 1.067$ & $* P=.0002$ \\
\hline
\end{tabular}

the cavernous sinus, sphenoid sinus, and even the brain. In general, large pituitary adenomas have a high incidence of invasion (14). However, large pituitary adenomas do not always demonstrate invasion, and even some small pituitary adenomas invade the cavernous sinus (15). Several investigators have studied to determine those factors that are associated with invasion, but reliable biologic markers predicting invasiveness are unknown.

Tumor-associated antigen RCAS1, isolated from $22-1-1$, acts as a ligand for a receptor present on normal peripheral lymphocytes such as T-, B-, and NK-cells. NK-cells and T-cells are thought to be important in tumor recognition and elimination at an early stage of cancer progression and metastasis (16). Human T- and B-cells do not express RCAS1, but the receptor expression was enhanced by activation of the lymphocytes. RCAS1 inhibited the in vitro growth of receptor-expressing cells and induced apoptotic cell death. Given these results, tumor cells may evade immune surveillance by expression of RCAS1, which would suppress clonal expression and induce apoptosis in RCAS1 receptor-positive immune cells.

Immunohistochemically, expression of RCAS1 has been detected in uterine and ovarian carcinomas, especially in invasive tumors $(10,11)$. However, RCAS1 has not been detected in normal uterine and ovarian tissues (10). In addition, RCAS1 is highly expressed on invasive carcinomas (11), and expression of RCAS1 is correlated with poor prognosis in uterine cancers (17). This circumstantial evidence indicates that RCAS1 on tumor cells may act as a defense by tumor cells against cells of the immune system (2).

Therefore, we paid particular attention to pituitary adenomas to study the expression of RCAS1 and invasion of tumor. As a result, we found that RCAS1 was expressed in $48 \%$ of pituitary adenomas but not expressed in normal pituitary glands. Expressions of RCAS1 were not correlated with type of pituitary adenoma, tumor size, and invasiveness. Ki-67 antigen detectable in all stages of the cell cycle except G0 is considered a useful proliferation marker. The MIB-1 antibody permits detection of Ki-67 antigen in formalin-fixed, paraffin-embedded tissues. In pituitary adenomas, several reports suggested that MIB-1 labeling index concords with cell proliferation $(18,19)$.

Our data showed a relationship between the expression of RCAS1 and MIB-1 index. Based on these factors, it may be anticipated that expression of RCAS1 as well as MIB-1 predicts the growth potential of individual pituitary adenomas. However, no relationship was evident between expression of RCAS1 and tumor invasiveness. Further investigation of proliferative potential and other factors related to invasiveness of pituitary adenomas is needed.

\section{REFERENCES}

1. Landolt AM, Shibata T, Kleihues P. Growth rate of human pituitary adenomas. J Neurosurg 1987;67:803-6.

2. Scheithauer BW, Kovacs KT, Laws ER Jr, Randall RV. Pathology of invasive pituitary tumors with special reference to functional classification. J Neurosurg 1986;65:733-44.

3. Thapar T, Kovacs K, Scheithauer BW, Stefaneanu L, Horvath E, Pernicone PJ, et al. Proliferative activity and invasiveness among pituitary adenomas and carcinomas: an analysis using the MIB-1 antibody. Neurosurg 1996;38:99-107.

4. Zhao D, Tomono Y, Nose T. Expression of P27 and Ki-67 in pituitary adenomas: an investigation of adenoma invasiveness. Acta Neurochir 1999;141:187-92.

5. Turner HE, Nagy Zs, Gatter KC, Esiri MM, Wass JAH, Harris AL. Proliferation, bcl-2 expression and angiogenesis in pituitary adenomas: relationship to tumor behavior. Br J Cancer 2000;82:1441-5.

6. Gerdes J, Schwab U, Lemke H, Stein H. Production of a mouse monoclonal antibody reactive with a human nuclear antigen associated with cell proliferation. Int J Cancer 1983; 31:13-20.

7. Gerdes J, Lemke H, Baisch H, Wacker H-H, Schwab U, Stein H. Cell cycle analysis of a cell proliferation-associated human nuclear antigen defined by the monoclonal antibody Ki-67. J Immunol 1984;133:1710-5.

8. Cattoretti G, Becker MHG, Key G, Duchrow M, Schluter C, Galle J, et al. Monoclonal antibodies against recombinant parts of the Ki-67 antigen (MIB 1 and MIB 3) detect proliferating cells in microwave-processed formalin-fixed paraffin sections. J Pathol 1992;168:357-63.

9. Nakashima M, Sonoda K, Watanabe T. Inhibition of cell growth and induction of apoptotic cell death by the human tumor-associated antigen RCAS1. Nature Med 1999;5:93842.

10. Sonoda K, Nakashima M, Kaku T, Kamura T, Nakano H, Watanabe T. A novel tumor associated antigen expressed in human uterine and ovarian carcinomas. Cancer 1996;77: 1501-9.

11. Sonoda K, Kaku T, Kamura T, Nakashima M, Watanabe T, Nakano H. Tumor-associated antigen 22-1-1 expression in the uterine cervical squamous neoplasias. Clin Cancer Res 1998;4:1517-20.

12. Sanno N, Teramoto A, Osamura RY. Clinical and cytofunctional classification of pituitary adenomas: proposal of a new classification. Acta Neurochir 1996;138:1186-92.

13. Sanno N, Osamura RY. Molecular pathology of the pituitary adenomas. Endocrine Pathol 1997;8:137-42.

14. Coudwell WT, Weiss MH. Strategies for the management of nonfunctioning pituitary adenomas. In: Cooper PR, editor. Contemporary diagnosis and management of pituitary adenomas. Rolling Meadows, IL: American Association of Neurological Surgeons; 1991. pp. 29-35.

15. Hirohata T, Uozumi T, Mukada K, Aria K, Kurisu K, Sinoda M, et al. Microprolactinoma invading the cavernous sinus: report of three cases. Neuro Med Chir 1992;32:10-12. 
16. Whiteside TL, Herberman RB. The role of natural killer cells in immune surveillance of cancer. Curr Opin Immunol 1995; 7:704-10.

17. Kaku T, et al. The prognostic of significance of tumorassociated antigen 22-1-1 expression in adenocarcinoma of the uterine cervix. Clin Cancer Res (in press).
18. Abe T, Sanno N, Osamura YR, Matsumoto K. Proliferative potential in pituitary adenomas: measurement by monoclonal antibody MIB-1. Acta Neurochir 1997;139:613-8.

19. Knosp E, Kitz K, Perneczky A. Proliferation activity in pituitary adenomas: measurement by monoclonal antibody Ki67. Neurosurg 1989;25:927-30. 